\title{
Influence of Tooth Loss and Unmet Treatment Needs on the Social Aspects of Quality of Life and Self-esteem in Adolescents
}

\author{
Running title: Impact of Tooth Loss on Quality of Life in Adolescence
}

Pavlovic Maja ${ }^{1}$, Matijevic Dusanka ${ }^{2}$, Vukovic Branislava $^{2}$, Mileusnic Ivan ${ }^{3}$, Gajic Milica ${ }^{4}$ and Jevremovic Ana ${ }^{1}$

1. Department of Prosthodontics, Faculty of Stomatology Pancevo, University Business Academy, Novi Sad 21000, Serbia

2. Department of Basic Sciences, Faculty of Stomatology Pancevo, University Business Academy, Novi Sad 21000, Serbia

3. Department of Periodontology, Faculty of Stomatology Pancevo, University Business Academy, Novi Sad 21000, Serbia

4. Department of Preventive and Pediatric Dentistry, Faculty of Stomatology Pancevo, University Business Academy, Novi Sad

21000, Serbia

\begin{abstract}
Adolescence represents specific period of life and development, when young person is going through physical, emotional and mental changes, risking poor general and oral health outcome that might affect quality of life. Negative effects of poor oral health are various: difficulties with speaking and eating, pain and malfunction. This might cause emotional and mental problems, leading to avoidance of speaking, smiling and socializing with friends. Cross-sectional study included 234 participants (15-16 years old). The research instruments used in the study were questionnaire and clinical examination. Questionnaire referred to socio-demographic characteristics of participants, their oral and general health related habits, self-evaluation of confidence and successfulness and effect of oral impacts on daily performances. Clinical examination was used to determine dental status in terms of tooth loss, need for prosthodontic rehabilitation and presence of dental malocclusion. Results: $24.6 \%$ (58) of adolescents had at least one tooth missing. Significant difference between the genders was obtained, as $32.5 \%$ girls had at least one tooth extracted compared to $8.1 \%$ of boys. Normative need for prosthodontic rehabilitation was present in $22.0 \%$ of subjects. Dental problems negatively affected their sleep and emotions (14.4\% and $10.2 \%$ few times in period of one month). Data analyses pointed one correlation between extracted teeth and psychosocial aspect of participants' life (difficulties and embarrassment when smiling, talking and spending time with friends, emotional problems). Unmet normative need for prosthodonic or orthodontic treatment affected participants' ability to sleep and relax. Percentage of adolescents with extracted teeth was high, as well as normative treatment need for prosthodontic rehabilitation. Poor dental status affected quality of life of adolescents, especially emotional and mental well-being. Dental service should provide sufficient information to adolescents about prevention of tooth loss and consequences of teeth extraction, not only within masticatory function but also concerning oral health related quality of life.
\end{abstract}

Key words: Adolescent, tooth loss, normative treatments need, quality of life.

\section{Introduction}

Adolescence is a specific period in life during which a young person is going through physical, emotional and mental changes. In childhood the most significant sources of information and behavioral role models are

Corresponding author: Maja Pavlovic, Ph.D., associate professor, research field: prosthodontics. parents and school. However, adolescents usually shift their priorities and behavioral patterns. Namely, influenced by popular youth culture and out of need to be accepted by peer groups, physical appearance becomes one of the top priorities in an adolescent's life so, consequently, they tend to care more for oral health [1]. Studies have shown that young people who had poor oral health had less self-confidence and lower 
self-esteem [2, 3].

Poor general and oral health can have a deleterious effect on an individual's quality of life. Children and adolescents are more vulnerable to the negative impacts of poor health, since they are going through a formative period in life. The negative effects of poor oral health are various: difficulties with speaking and eating, pain and impaired function. Beside those, poor oral health, and consequent poor physical appearance especially due to tooth loss, can cause emotional and mental problems in young individuals, so they will avoid speaking, smiling and spending time with friends [4-6].

Different scales have been developed in order to assess the impact of oral health on the overall quality of life. The Oral Health-Related Quality of Life questionnaire [7] measures subjective indicators related to the effects of a person's oral health status on various aspects of life: physical, mental, emotional and social [8]. Oral Impacts on Daily Performances (OIDP) questionnaire is specifically tailored for the young population with high reliability and validity of results. It measures the frequency and severity of problems caused by the diminished oral health which the respondents experienced in the preceding six months, such as difficulties in eating, speaking, laughing, maintenance of oral hygiene, having trouble to sleep and relax, changes in emotional state, development of social contacts and academic performance [9]. Most of the studies which used the OIDP questionnaire explored the possible effect of decayed, missing, and filled teeth (DMFT) index score on adolescents' daily activities [10-13]. They found that adolescents with a higher DMFT score reported a higher impact on everyday life, mostly in terms of inadequate chewing performance, anxiety, feeling of embarrassment and mental problems.

Some investigators focused on the effects of tooth loos and prosthodontic treatment needs on the oral health-related quality of life in adolescents. These studies indicated that adolescents with more than 2 or 3 extracted teeth had a higher emotional stress level compared to those with no teeth extracted [14, 15]. Furthermore, studies which investigated the impact of prosthetic rehabilitation on the subsequent quality of life concluded that adolescents with adequate prosthodontic rehabilitation reported improvements, especially in psychosocial and physiological aspects of life $[16,17]$.

The aim of this study was to determine the percentage of adolescents with missing teeth and unmet normative prosthodontic treatment needs and to explore the consequent relationship between tooth loss and adolescents' oral health-related quality of life within the same population.

\section{Materials and Methods}

This cross-sectional study was conducted in Pancevo, Serbia during May and June of 2016. Randomly selected adolescents attending the first grade of public high schools in Pancevo (15-16 years old) were included in the study. The total number of students asked to participate in the study was 400 with 278 accepting, which was the response rate of $69.5 \%$.

The study was approved by The Ethics Committee of the Faculty of Stomatology, Pancevo (Decision \#286/15). Also, a parental written consent from all participants had been obtained prior to the beginning of the study. The questionnaires with incomplete information regarding gender, age, dental habits and OIDP were excluded from the study, reducing the final number of participants to 234 .

The research instruments used in the study were the questionnaire filled out independently by the children (parents did not participate in the study in any way) and the clinical examination. A pilot study including 12 participants had been conducted previously, in order to verify the questionnaire, check its clarity and make simplified formulations of questions where necessary. Consequently, a final version of the questionnaire contained seven sections with a certain number of questions. Each section was targeted at a specific 
category: socioeconomic living conditions and demographic data, oral hygiene practises, dietary habits, healthy living, perception of success, general health knowledge and OIDP questionnaire. The OIDP questionnaire was used to evaluate the impact of oral health on daily activities and emotional and social segments of a subject's life. The adolescents rated how often due to the problems related to their teeth and oral tissues during the preceding six months they experienced problems with: eating and enjoying food, speaking, tooth brushing, sleeping and relaxing, laughing, going through certain emotional situations, socializing and completing school tasks. The answers were ranked on a scale from 0 to 4 , where 0 means never or less than 1 time per month; 1 means once or twice per month; 2 means 1 to 2 times per week; 3 means 3 to 4 times a week and 4 means almost every day. A total score was obtained through the addition of individual responses, with the possible score ranging from 0 to 32. A higher score meant that the participants experienced more problems in the investigated activities.

The clinical examination was performed by two calibrated researchers (MP and BV) and was used to determine the dental status and to record tooth loss. Prior to collecting the data, both researchers had been trained in the consistency of data collection, as well as in uniform assistance to the participants during the filling of the questionnaire. Inter-examiner agreement was confirmed during theoretical discussions when examiners showed photographic slides containing clinical examples of each parameter to be investigated in the study. During the discussions the examiners' knowledge was evaluated and they were instructed in the criteria and examination methods to be used so as to achieve an initial standardization [18].

The clinical examination, using a dental mirror and a dental probe [19], was performed in a classroom during daylight while the subjects were seated in school chairs next to a window. The following data were collected: extracted teeth, the presence of prosthodontic restorations, existing malocclusions, as well as the need for any prosthodontic or orthodontic treatment. In a few cases, fractured teeth, even though no radiographic images were available at the time of the examinations, were counted as present. The number of extracted teeth, the need for a prosthetic rehabilitation, malocclusion and the presence of an orthodontic appliance were designated as dependent variables.

All data were analyzed using the SPSS Statistics software package (version 20.0). The data from the questionnaire were designated as independent variables, while the clinical data were designated as dependent variables. Depending on the parameters, a Pearson's chi-square test was used in the form of a test of goodness of fit and a contingency table. The differences between the frequencies of one or two parameters within the group of nonparametric data (questionnaire) were tested. A signed-rank test was used as a nonparametric statistical test for independent variables. A nonparametric correlation test was used to analyze the relationship between the examined characteristics depending on the data distribution. A logistic regression analysis was used to determine the nature of influence, which the independent variables had on the examined clinical parameters (dependent variables). Each section of questionnaire was given a sum of score and each sum was determined as an independent variable. A higher score of the independent variables pointed out to a positive influence on the dependent variables, except for the OIDP score (number 7) whose score had an inverse (negative) effect on the dependent variables.

\section{Results}

In total, 234 participants participated in the study: 74 (31.6\%) males and 160 (68.4\%) females. Large families, consisting of five or more members, predominated $(96.6 \%)$. Even though $68.6 \%$ reported a country-average monthly income, when asked about the employment status of their parents $69.5 \%$ admitted 
living with parents who were unemployed. Almost all of the participants $(93.2 \%)$ were satisfied with their living conditions. Surprisingly, $57.6 \%$ stated that interpersonal family relationships were the most important factor affecting their personal happiness and only $18.6 \%$ pointed out that the opinion of their peers was paramount for their feeling of happiness and fulfillment.

Most of the participants stated that they had satisfactory oral hygiene practices. Only $0.8 \%$ admitted that they never brushed their teeth, while $99.2 \%$ reported brushing at least twice daily. The occasional use of complementary oral hygiene products, such as mouth rinses and dental floss, was reported by $64.4 \%$ of the respondents. Roughly half of them $(50.8 \%)$ visited their dentists twice a year for regular checkups.

At the time of the clinical examination almost a quarter $(24.6 \%)$ or 58 participants had at least one tooth missing, with significant differences $(p \leq 0.05)$ between the genders $-32.5 \%$ females compared to $8.1 \%$ males. Consequently, $22 \%$ of the sample presented with a normative need for prosthetic rehabilitation showing the same inter-gender differences $(p \leq 0.05)-28.8 \%$ females compared to $8.1 \%$ males. Crowding, increased overbite and overjet, and rotated teeth were noted in $68.6 \%$ of the participants but only $3.6 \%$ had an orthodontic appliance (either fixed or mobile).

Overall, untreated caries was the predominant reason for tooth extractions (82.8\%) and the sole reason for extractions in the male subpopulation. A significant difference $(p \leq 0.05)$ existed in the female subpopulation where untreated caries caused $81.5 \%$ of the extractions. Furthermore, extraction orthodontic treatment caused $13.8 \%$ of lost teeth in the whole sample, $14.8 \%$ in females and none in males.

When asked to explain the reasons for the lack of prosthodontic or orthodontic treatment $67.7 \%$ stated that they had never been given any explanation about the importance of such therapies and $12.9 \%$ cited lack of finances. A small number $(6.5 \%)$ of the participants thought that they did not need any kind of such a treatment. Conversely, $12.9 \%$ stated that some kind of prosthodontic or orthodontic therapy had been planned for the near future.

The results regarding the self-perceived level of self-esteem and confidence showed that although $69.5 \%$ of the participants thought of themselves as being successful, half of them were not satisfied with their results in school and almost all of them (94.9\%) thought that they could have done better with significant inter-gender differences $-97.5 \%$ of females compared to $89.2 \%$ of males.

The results of the OIDP questionnaire showed that only $16.9 \%$ of the participants rarely had any difficulties while tooth brushing; females more often than males-21.2\% compared to $8.1 \%$. However, dental problems more frequently negatively affected their sleep (14.4\%) and emotions (10.2\%). Again, females had more problems with sleep and emotions $(18.8 \%$ and $13.8 \%$, respectively) than males $(5.4 \%$ and $2.7 \%)(p \leq 0.05)$. The participants in this study did not point out any noticeable problems with eating, smiling, speaking and spending time with friends in relation to the dental status.

The results of nonparametric correlation testing are shown in Table 1. The number of extracted teeth was correlated to gender $(p \leq 0.05)$, use of complementary oral hygiene products $(p \leq 0.05)$ and reasons for dental visits $(p \leq 0.05)$.

The normative treatment needs were correlated to reasons for dental visits $(p \leq 0.05)$ and consequent treatment. Dentoalveolar anomalies were correlated to oral hygiene and dental therapies. The presence of orthodontic appliances was correlated to reasons and frequency of dental visits, as well as the duration of tooth brushing ( $p \leq 0.05$ ).

The investigation of possible correlations between the dental status and participants' self-confidence showed the existence of a strong connection between tooth loss and personal perception of success (Table 2). Unmet normative prosthodontic treatment needs were strongly related to the satisfaction with school results 
Table 1 Nonparametric correlation between oral health habits, gender and dental status.

\begin{tabular}{|c|c|c|c|c|c|c|c|c|c|c|}
\hline & & Gender & $\begin{array}{l}\text { Frequency } \\
\text { of tooth } \\
\text { brushing }\end{array}$ & $\begin{array}{l}\text { Use of accessory } \\
\text { hygiene products }\end{array}$ & $\begin{array}{l}\text { Last } \\
\text { check-up }\end{array}$ & $\begin{array}{l}\text { Present } \\
\text { dental } \\
\text { fear }\end{array}$ & $\begin{array}{l}\text { Unpleasant } \\
\text { experience }\end{array}$ & $\begin{array}{l}\text { Reason for } \\
\text { tooth } \\
\text { extraction }\end{array}$ & $\begin{array}{l}\text { Reason why } \\
\text { treatment was } \\
\text { not done }\end{array}$ & $\begin{array}{l}\text { Reason } \\
\text { for dental } \\
\text { visit } \\
\end{array}$ \\
\hline \multirow{3}{*}{ Extracted teeth } & Ro & -0.263 & -0.014 & -0.192 & 0.026 & 0.006 & 0.054 & -0.086 & -0.169 & -0.184 \\
\hline & $p$ & $0.000 * *$ & 0.834 & 0.003 & 0.692 & 0.927 & 0.410 & 0.521 & 0.188 & 0.005 \\
\hline & $\mathrm{N}$ & 234 & 236 & 236 & 236 & 236 & 236 & 58 & 62 & 236 \\
\hline \multirow{3}{*}{$\begin{array}{l}\text { Normative } \\
\text { treatment need }\end{array}$} & Ro & -0.231 & -0.019 & -0.032 & -0.013 & 0.090 & 0.138 & 0.807 & 0.566 & -0.210 \\
\hline & $p$ & $0.000 * *$ & 0.777 & 0.626 & 0.844 & 0.170 & 0.034 & 0.000 & 0.000 & 0.001 \\
\hline & $\mathrm{N}$ & 234 & 236 & 236 & 236 & 236 & 236 & 58 & 62 & 236 \\
\hline \multirow{3}{*}{$\begin{array}{l}\text { Dentoalveolar } \\
\text { anomalies }\end{array}$} & Ro & -0.012 & -0.083 & -0.121 & 0.081 & 0.084 & -0.067 & 0.225 & 0.310 & 0.029 \\
\hline & $p$ & 0.857 & 0.204 & 0.064 & 0.215 & 0.201 & 0.306 & 0.090 & 0.014 & 0.653 \\
\hline & $\mathrm{N}$ & 234 & 236 & 236 & 236 & 236 & 236 & 58 & 62 & 236 \\
\hline \multirow{3}{*}{$\begin{array}{l}\text { Present } \\
\text { orthodontic } \\
\text { appliance }\end{array}$} & Ro & -0.128 & 0.045 & 0.041 & 0.122 & 0.096 & -0.095 & -0.396 & -0.333 & -0.014 \\
\hline & $p$ & 0.051 & 0.493 & 0.526 & 0.062 & 0.140 & 0.147 & 0.002 & 0.008 & 0.827 \\
\hline & $\mathrm{N}$ & 234 & 236 & 236 & 236 & 236 & 236 & 58 & 62 & 236 \\
\hline
\end{tabular}

$\mathrm{N}$ : number of participants; $* *: p \leq 0.05$.

Table 2 Nonparametric correlation between participants' self-confidence and dental status.

\begin{tabular}{llllllll}
\hline & & $\begin{array}{l}\text { Personal } \\
\text { success }\end{array}$ & $\begin{array}{l}\text { Results in } \\
\text { school }\end{array}$ & $\begin{array}{l}\text { Better results } \\
\text { in school }\end{array}$ & $\begin{array}{l}\text { Success depends } \\
\text { on: }\end{array}$ & $\begin{array}{l}\text { Living conditions } \\
\text { satisfaction }\end{array}$ & $\begin{array}{l}\text { What makes subject } \\
\text { happy }\end{array}$ \\
\hline \multirow{2}{*}{ Extracted teeth } & Ro & -0.126 & 0.030 & 0.043 & -0.084 & -0.081 & 0.086 \\
& $p$ & $0.054^{*}$ & 0.645 & 0.516 & 0.198 & 0.215 & 0.189 \\
& $\mathrm{~N}$ & 236 & 236 & 236 & 236 & 236 & 236 \\
Normative & Ro & -0.041 & -0.139 & -0.156 & -0.109 & -0.101 & 0.029 \\
treatment need & $p$ & 0.536 & 0.033 & $0.016^{*}$ & $0.095^{*}$ & 0.123 & 0.656 \\
\hline \multirow{2}{*}{$\begin{array}{l}\text { Dento-alveolar } \\
\text { anomalies }\end{array}$} & $\mathrm{N}$ & 236 & 236 & 236 & 236 & 236 & 236 \\
\hline Present & $\mathrm{R}$ & 0.020 & -0.185 & -0.073 & 0.033 & -0.037 & -0.132 \\
orthodontic & $\mathrm{N}$ & 236 & 236 & 236 & 236 & 0.572 & $0.043 *$ \\
appliance & $\mathrm{R}$ & 0.024 & 0.128 & 0.043 & -0.168 & 0.051 & 236 \\
\hline
\end{tabular}

$\mathrm{N}$ : number of participants; *: $p \leq 0.05$.

and perception of influencing factors. School performance was related to the present dental malocclusion and the presence of an orthodontic appliance.

Although only a few participants reported problems in performing their usual daily activities due to the dental status and oral health related problems, correlation data analysis pointed to the correlation between tooth loss and psychosocial aspects of participants' life (Table 3). Unmet normative needs for prosthodontic or orthodontic treatment affected participants' ability to sleep, while dental malocclusions affected oral health habits and psychosocial aspects of life.

In order to determine the nature of the established correlations, data were processed using the method of logistic regression. The number of extracted teeth was positively impacted by a higher score of variable 2 (oral hygiene habits) and a lower score of variable 7 (OIDP questionnaire) (Table 4). Conversely, a higher score of variable 7 had a negative impact on normative need for prosthodontic treatment, i.e. raising its value. However, a lower socioeconomic status (variable 1) also caused more need for a prosthodontic treatment (Table 5). Those belonging to lower socioeconomic strata (variable 1) had their teeth extracted because of 
Table 3 Non-parametric correlation between OIDP questionnaire and dental status.

\begin{tabular}{|c|c|c|c|c|c|c|c|c|}
\hline & & $\begin{array}{l}\text { Difficulties } \\
\text { with eating }\end{array}$ & $\begin{array}{l}\text { Difficulties } \\
\text { with speaking }\end{array}$ & $\begin{array}{l}\text { Difficulties } \\
\text { during tooth } \\
\text { brushing }\end{array}$ & $\begin{array}{l}\text { Difficulties } \\
\text { with sleeping } \\
\text { and relaxing }\end{array}$ & $\begin{array}{l}\text { Avoiding } \\
\text { smiling and } \\
\text { speaking }\end{array}$ & $\begin{array}{l}\text { Having } \\
\text { emotional } \\
\text { problems } \\
\end{array}$ & $\begin{array}{l}\text { Enjoying } \\
\text { friends' } \\
\text { company }\end{array}$ \\
\hline & Ro & -0.083 & -0.137 & -0.033 & -0.100 & -0.159 & -0.177 & -0.154 \\
\hline \multirow[t]{2}{*}{ Extracted teeth } & & 0.206 & $0.035^{*}$ & 0.612 & 0.126 & $0.014 *$ & $0.006^{*}$ & $0.018^{*}$ \\
\hline & $\mathrm{N}$ & 236 & 236 & 236 & 236 & 236 & 236 & 236 \\
\hline \multirow{3}{*}{$\begin{array}{l}\text { Normative } \\
\text { treatment need }\end{array}$} & Ro & -0.061 & -0.064 & 0.038 & -0.131 & -0.025 & -0.028 & -0.017 \\
\hline & $p$ & 0.348 & 0.329 & 0.559 & 0.044 & 0.705 & 0.671 & 0.801 \\
\hline & $\mathrm{N}$ & 236 & 236 & 236 & 236 & 236 & 236 & 236 \\
\hline \multirow{3}{*}{$\begin{array}{l}\text { Dento-alveola } \\
\mathrm{r} \text { anomalies }\end{array}$} & Ro & -0.066 & -0.076 & -0.129 & -0.155 & -0.037 & 0.108 & 0.038 \\
\hline & $p$ & 0.313 & 0.244 & $0.048 *$ & $0.017 *$ & 0.573 & $0.097 *$ & 0.566 \\
\hline & $\mathrm{N}$ & 236 & 236 & 236 & 236 & 236 & 236 & 236 \\
\hline \multirow{3}{*}{$\begin{array}{l}\text { Present } \\
\text { orthodontic } \\
\text { appliance }\end{array}$} & Ro & -0.005 & 0.043 & -0.221 & 0.084 & -0.142 & -0.075 & -0.316 \\
\hline & $p$ & 0.942 & 0.508 & $0.001 *$ & 0.196 & $0.029 *$ & 0.250 & $0.000 *$ \\
\hline & $\mathrm{N}$ & 236 & 236 & 236 & 236 & 236 & 236 & 236 \\
\hline
\end{tabular}

$\mathrm{N}$ : number of participants; $*$ : $p \leq 0.05$.

Table 4 Logistic regression showing nature of connection between independent variables and extracted teeth (dependent variable).

\begin{tabular}{|c|c|c|c|c|c|c|c|c|c|}
\hline & & \multirow{2}{*}{ B } & \multirow{2}{*}{ S.E. } & \multirow{2}{*}{ Wald } & \multirow{2}{*}{ df } & \multirow{2}{*}{$p$} & \multirow{2}{*}{ OR } & \multicolumn{2}{|c|}{$95 \%$ CI for OR } \\
\hline & & & & & & & & Lower & Upper \\
\hline \multirow{8}{*}{ Step 1} & Score 1 & 0.312 & 0.069 & 2.194 & 1 & 0.148 & 0.246 & 0.089 & 0.425 \\
\hline & Score 2 & 0.137 & 0.054 & 9.020 & 1 & $0.008 * *$ & 1.991 & 0.880 & 3.117 \\
\hline & Score 3 & -0.177 & 0.028 & 1.278 & 1 & 0.136 & 0.876 & 0.736 & 1.042 \\
\hline & Score 4 & 0.1453 & 0.137 & 0.011 & 1 & 0.890 & 1.034 & 0.810 & 1.320 \\
\hline & Score 5 & -0.088 & 0.119 & 0.257 & 1 & 0.454 & 0.940 & 0.745 & 1.186 \\
\hline & Score 6 & -0.033 & 0.145 & 0.223 & 1 & 0.554 & 0.952 & 0.717 & 1.265 \\
\hline & Score 7 & -0.249 & 0.039 & 15.147 & 1 & $0.000 * *$ & 1.644 & 0.749 & 2.188 \\
\hline & Constant & 0.339 & 0.074 & 0.044 & 1 & 0.887 & 0.914 & 0.089 & 0.425 \\
\hline
\end{tabular}

CI: confidence interval; OR: odds ratio; $* *: p \leq 0.05$.

Table 5 Logistic regression showing nature of connection between independent variables and normative treatment need (dependent variable).

\begin{tabular}{|c|c|c|c|c|c|c|c|c|c|}
\hline & \multirow{2}{*}{ B } & \multirow{2}{*}{ S.E. } & \multirow{2}{*}{ Wald } & \multirow{2}{*}{$\mathrm{df}$} & \multirow{2}{*}{$p$} & \multirow{2}{*}{ OR } & \multirow{2}{*}{ B } & \multicolumn{2}{|c|}{ 95\% C.I. OR } \\
\hline & & & & & & & & Lower & Upper \\
\hline \multirow{8}{*}{ Step 1} & Score 1 & 0.418 & 0.198 & 13.449 & 1 & $0.000 *$ & 1.340 & 1.050 & 2.555 \\
\hline & Score 2 & 0.014 & 0.075 & 0.755 & 1 & 0.385 & 0.150 & 0.029 & 0.211 \\
\hline & Score 3 & -0.059 & 0.021 & 0.997 & 1 & 0.159 & 0.825 & 0.678 & 1.003 \\
\hline & Score 4 & 0.138 & 0.128 & 0.744 & 1 & 0.376 & 1.459 & 0.863 & 1.479 \\
\hline & Score 5 & 0.035 & 0.010 & 0.470 & 1 & 0.493 & 1.013 & 0.847 & 1.410 \\
\hline & Score 6 & 0.251 & 0.288 & 2.085 & 1 & 0.149 & 1.002 & 0.927 & 1.646 \\
\hline & Score 7 & -0.458 & 0.145 & 7.511 & 1 & $0.015^{*}$ & 0.879 & 0.842 & 1.603 \\
\hline & Constant & -4.061 & 2.270 & 6.045 & 1 & 0.001 & 0.004 & & \\
\hline
\end{tabular}

CI: confidence interval; OR odds ratio; *: $p \leq 0.05$. 
Table 6 Impact of independent variables on reasons for teeth extraction- logistic regression.

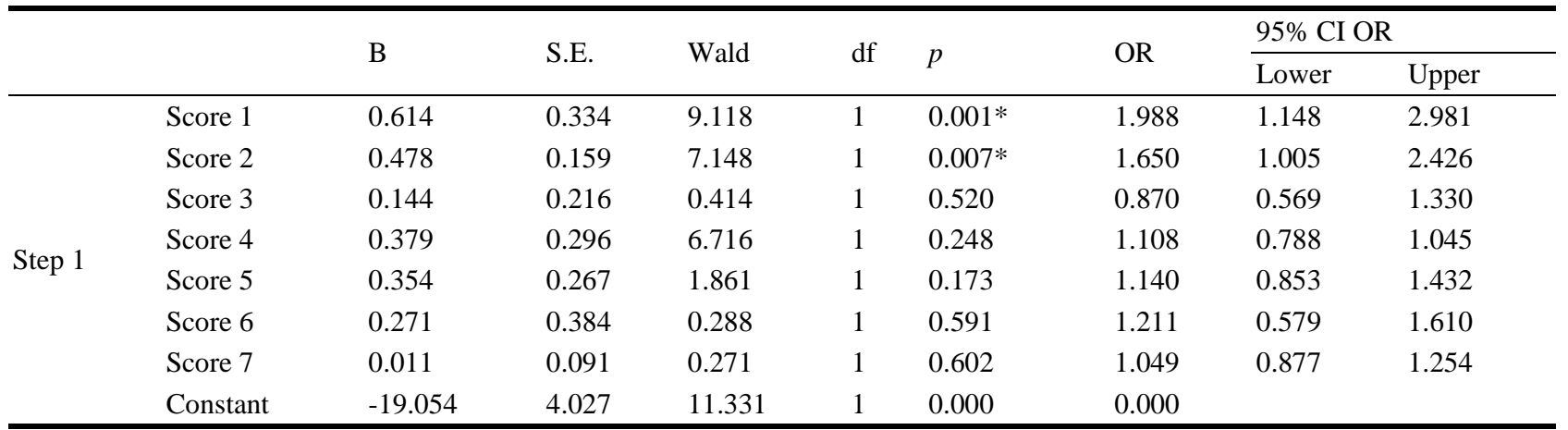

CI: confidence interval; OR: odds ratio; *: $p \leq 0.05$.

caries complications, while those with better oral hygiene (variable 2) had their teeth extracted because of planned orthodontic treatment (Table 6).

\section{Discussion}

The socioeconomic status of the study population of this cross-sectional study was an essential part of the overall design. The random sample analysis showed that two-thirds $(69.5 \%)$ lived with parents who were unemployed and $96.6 \%$ of them lived in large families with more than five members. This implies that most of the participants belonged to the lower socioeconomic strata. Although instead of taking a DMFT score the data gathered were the number of extracted teeth and the assessment of prosthodontic treatment needs, the negative influence of a lower economic status on oral health habits and behavior was in concert with previous studies [20-22]. Before the economic crisis, which hit Serbia in the last two decades, Pancevo had been a thriving industrial hub with low unemployment rates and a well-educated workforce. Unfortunately, the circumstances have changed for the worse, affecting the socioeconomic status of the inhabitants. Consequently, the lower family income and educational level of parents affected and shaped their attitude toward children's oral health and their ability to afford an expensive prosthodontic rehabilitation.

This study concentrated on prosthodontic treatment needs arising from missing teeth. Therefore, DMFT as an index of overall dental condition could not be used and the number of missing teeth was utilized instead.
Almost a quarter of the studied population (24.6\%) had at least one tooth extracted, which was similar to a Brazilian study [23] where $29 \%$ were found to be missing at least one tooth. Other studies reported a different percentage of adolescents with missing teeth, ranging from $16 \%$ to $39 \%$, depending on the clinical parameters taken into consideration [24-26]. To some extent the discrepancy in these findings could be explained by different sample sizes, investigated areas (urban vs. rural), socioeconomic status, etc. Gender-wise, we found that girls were worse off $(32.5 \%)$ than boys $(8.1 \%)$, which was an unexpected result since girls are considered to be more interested in healthcare topics, whether general or oral.

The number of subjects in need of a prosthodontic treatment was high $(22 \%)$ with a significant difference between genders: $28.8 \%$ for girls compared to $8.1 \%$ for boys. There are limited data in the literature about the normative prosthodontic treatment needs in adolescents. Namely, based on a national survey in Brazil, De Sousa Barbosa [15] concluded that there was a decrease in the normative prosthetic rehabilitation need in adolescents. Conversely, with regard to our results, Vazquez [27] reported that $13.7 \%$ of the population between the ages of 15 and 17 were in need of a prosthodontic rehabilitation. Essentially, the results of the present cross-sectional regional study could not be extrapolated on the national level and therefore are hard to compare to the cited national studies. As many studies have shown [23, 25, 28], the most common reasons for tooth extractions in young 
populations are complications due to caries and orthodontic treatment. Our results reiterated these findings, as the majority of the teeth were lost because of complicated carious lesions. An interesting finding was that caries complications were the only reason for tooth extractions among boys, while $14.8 \%$ of girls had extractions due to the planned orthodontic treatment. This finding is consistent with previous studies, which evaluated the dental status of adolescents and concluded that girls were more concerned about health, appearance and aesthetics [26, 29].

Contradictory to the previous findings regarding tooth loss and normative treatment needs [30, 31], the subjects in our study reported good oral hygiene habits with $99.2 \%$ brushing twice a day. This disagreement in the dental status and the subjects' self-evaluation of oral health habits could be explained in two ways: the influence of popular culture and mass media, or the desire to answer the questions in a more acceptable way. Our data about oral hygiene habits differ from similar studies [30, 31], which showed that adolescents did not visit their dentists regularly. In part, this discrepancy could be explained by the rural nature of their study population, which had limited access to dental care. Furthermore, this population had limited financial means and lacked the necessary information regarding the importance of good oral health.

When questioned about the reasons for the lack of prosthodontic or orthodontic treatment most subjects in our study (67.7\%) cited insufficient information regarding the importance of such a treatment which emphasizes the importance of preventive and educational programs about oral health. Since prosthodontic treatment is not covered by the National Health Service in Serbia, dentists in schools are the first to inform and advise adolescents on how to maintain good oral health. Tooth loss presents a permanent problem, which can trigger further malfunctions and deterioration of oral health making information about the benefits of adequate treatment, especially to the young, essential in the preservation of good oral health and masticatory function throughout life.

Two-thirds of the participants in our study rated themselves as successful $(69.5 \%)$ but they also stated that they could have had better results in school (94.9\%). Although most of them belonged to the lower socioeconomic strata they were mostly satisfied with their living conditions. Unexpectedly, although adolescence is a period in life when a young person expresses a strong need to be primarily accepted by peer groups, $57.6 \%$ of them stated that their family was the most important factor for the sentiment of wellbeing. This finding was significant and consistent with similar studies [32, 33] because families can strongly affect the forming and establishment of good oral habits and health.

The results of the OIDP questionnaire were in concert with similar studies $[4,6,10]$, which investigated the impact of oral health on daily performance. Contrary to our results where only $10.2 \%$ of the subjects felt emotional problems caused by diminished oral health, Chukwumah et al. [12] and Mota Veloso et al. [13] reported a much higher percentage in their samples $(66.8 \%$ and $94.9 \%$ respectively). In these studies a DMFT score was recorded, while only tooth loss was considered in our sample making these findings hard to compare. However, it can be assumed that if decayed and teeth with fillings were added, our score would proportionately be higher.

Expectedly, we found a correlation between tooth loss and oral health habits. Namely, better oral hygiene (tooth brushing, the use of accessory oral hygiene products and regular check-ups) had a positive effect on tooth loss emphasizing once again the importance of prevention. Furthermore, the analysis pointed out to the existence of a correlation between tooth loss and self-confidence of the participants. Although only a few participants reported problems in the performance of daily activities caused by dental problems it was evident that tooth loss and unmet normative prosthodontic treatment needs affected the emotional 
and psychosocial aspects of a young person's life. These data were consistent with the findings of Tuchtenhagen [11] and Chukumwah [12]. However, even though the examined clinical parameters were not the same it could be said that worse oral health status affected every aspect of life.

The small number of participants in this study was representative of the city of Pancevo, but it also represents its chief limitation. However, this survey offers a useful insight into the dental status of an average adolescent in an urban area in Serbia and its impact on daily activities. Consequently, it would be beneficial to enlarge this study and include a larger sample in various regions of the country. This would enable a more accurate determination of the factors, which affect tooth loss, and treatment needs as well as their direction. The collected data would provide more accurate information about the specific correlation between tooth loss, and emotional status and quality of life of adolescents. The results of such a comprehensive study would prove useful for the planning of educational and preventive programs aimed at a specific age group. Furthermore, recommendations could be formulated for dental health planners about the means to reduce the incidence of permanent teeth extraction at an early age and how to educate young population on the importance of a timely treatment.

\section{Conclusions}

The percentage of adolescents with extracted teeth in Serbia was high considering the age of the sample. Consequently, the normative need for a prosthodontic rehabilitation was also high indicating the failure of public dental services to provide adequate and timely treatment, as well as information regarding restorative options.

Poor dental status was directly correlated to socio-demographic characteristics and affected the quality of life of adolescents, especially emotional and mental aspects.
Public dental services can reduce the extraction rate in a young population through educational and prevention programs and consequently diminish the normative need for subsequent prosthodontic or orthodontic treatment.

The improvement methods should be found from the aspects that affect the patients' quality of life and tailored accordingly so that better results can be obtained.

\section{References}

[1] Klages, U., Bruckner, A., Guld, Y., et al. 2005. "Dental Esthetics, Orthodontic Treatment and Oral Health Attitudes in Young Adults." Am J Orthod and Dentofacial Orthop 128 (4): 442-9.

[2] Dumitrescu, A. L., Dogaru, C. B., Duta, C., et al. 2014. "The Inter-relationships between Body Dissatisfaction, Body Image Disturbance and Oral Health." Procedia-Social and Behavioral Sciences 127: 368-72.

[3] Kallestal, C., Dahlgren, L., and Stenlund, H. 2006. "Oral Health Behavior and Self-esteem in Swedish Adolescents over 4 Years." J Adolesc Health 38 (5): 583-90.

[4] Nagarajappa, R., Batra, M., Sanadhya, S., Daryani, H., and Ramesh, G. 2015. "Relationship between Oral Clinical Conditions and Daily Performance among Young Adults in India: A Cross-sectional Study." J Epidemiol and Glob Health 5 (4): 347-57.

[5] Bianco, A., Fortunato, L., Nobile, C., et al. 2010. "Prevalence and Determinants of Oral Impacts on Daily Performance: Results from a Survey Among School Children in Italy.” Eur J Public Health 20 (5): 595-600.

[6] Hongxing, L., List, T., Nillson, L. M., et al. 2014. "Validity and Reliability of OIDP and OHIP-14: A Survey of Chinese High School Students." BMC Oral Health 14 (1): 158 .

[7] Alves, L. S., Naile, D. T., Susin, C., et al. 2013. "Association among Quality of Life, Dental Caries Treatment and Intraoral Distribution in 12-Year-Old South Brazilian Schoolchildren." Community Dent Oral Epidemiol 41 (1): 22-9.

[8] Alsumait, A., El-Salhy, M., and Amin, M. 2015. "Long Term Effects of School Based Oral Health Program on Oral Health Knowledge and Practices and Oral Health-Related Quality of Life." Med Princ Pract 24: 362-8.

[9] Rosel, E., Tsakos, G., Bernabe, E., et al. 2010. “Assessing the Level of Agreement between the Self- and Interview-Administered Child-OIDP.” Community Dent Oral Epidemiol 38 (4): 340-7.

[10] Peres, K. G., Cascaes, A. M., Leao, A. N., et al. 2013. 
"Sociodemographic and Clinical Aspects of Quality of Life Related to Oral Health in Adolescents." Rev Saude Publica 47 (3): 19-28.

[11] Tuchtenhagen, S., Bresolin, C. R., Tomazoni, F., et al. 2015. "The Influence of Normative and Subjective Oral Health Status on Schoolchildren's Happiness." BMC Oral Health 15: 15.

[12] Chukwumah, N. M., Folayan, M. O., Oziegbe, E. O., et al. 2016. "Impact of Dental Caries and Its Treatment on the Quality of Life of 12- to 15-Year Old Adolescents in Benin, Nigeria.” Int J Paediatr Dent 26 (1): 66-76.

[13] Mota-Veloso, I., Soares, M. E., Alencar, B. M., et al. 2016. "Impact of Untreated Dental Caries and Its Clinical Consequences on the Oral Health-Related Quality of Life of Schoolchildren Aged 8-10 Years." Qual Life Res 25 (1): 193-9.

[14] Alsumait, A., El-Salhy, M., Raine, K., et al. 2015. "Impact of Dental Health on Children's Oral Health-Related Quality of Life: A Cross-sectional Study." Health Qual Life Outcomes 13: 98.

[15] De Sousa, R. M. L., Rando-Meirelles, M., Nascimento, T. L. H., et al. 2014. "Dental Caries and Treatment Needs in Adolescents from the State of Sao Paolo, Brazil." Rev Saude Publica 47 (3): 50-8.

[16] Ramos-Jorge, J., Paiva, S. M., Tatanounoff, J., et al. 2014. "Impact of Treated/Untreated Traumatic Dental Injuries on Quality of Life among Brazilian Schoolchildren." Dent Traumatol 30 (1): 27-31.

[17] Lundgren, G. P., Karsten, A., and Dahloff, G. 2015. "Oral Health-Related Quality of Life before and after Crown Therapy in Young Patient with Amelogenesis Imperfecta." Health Qual Life Outcomes 13: 197.

[18] Assaf, V. A., Tagliaferro, E. P., Meneghim, M. C., et al. 2007. "A New Approach for Interexaminer Reliability Data Analysis on Dental Caries Calibration." J Appl Oral Sci 15 (6): 480-5.

[19] WHO. 1999. International Classification of Functioning, Disability and Health (ICF). Geneva: WHO.

[20] Dodd, V. J., Logan, H., Brown, C. D., et al. 2014. "Perceptions of Oral Health, Preventive Care and Care Seeking Behaviors among Rural Adolescents." J Sch Health 84 (12): 802-9.

[21] Riediger, N. D., Shooshtari, S., and Mogadishia, N. 2007. "The influence of Sociodemographic Factors on Pattern of Fruit and Vegetable Consumption in Canadian Adolescents." J Am Diet Assoc 107 (9): 1511-8.

[22] Obafunke, D., Ajay, D., Bankole, O., et al. 2010. "Dental
Service Utilization among Junior Secondary School Students in Ibadan, Nigeria." Pediatric Dental Journal 20 (2): 177-81.

[23] Susin, C., Haas, A. N., Opermann, R. V., et al. 2006. "Tooth Loss in a Young Population from South Brazil." J Public Health Dent 66 (2): 110-5.

[24] Hessari, A., Venkalahti, M. M., Eghbal, M. J., et al. 2008. "Oral Health and Treatment Needs among 18-Year-Old Iranians." Med Princ Pract 17 (4): 302-7.

[25] Halicioglu, K., Toptas, O., Akkas, I., et al. 2014. "Permanent First Molar Extraction in Adolescents and Young Adults and Its Effects on the Development of Third Molar." Clin Oral Invest 18 (5): 1489-94.

[26] Barbato, P. R., and Peres, M. A. 2009. "Tooth Loss and Associated Factors in Adolescents: A Brazilian Population-based Oral Health Survey." Rev Saude Publica 43 (1): 1-9.

[27] Vazquez, I., Cortellazzi, K. L., Kaida, A. K., et al. 2015. "Individual and Contextual Factors Related to Dental Caries in Underprivileged Brazilian Adolescents." BMC Oral Health 15: 6.

[28] Hou, R., Mi, Y., Xu, G., et al. 2014. "Oral Health Survey and Oral Health Questionnaire for High School Students in Tibet, China." Head Face Med 19 (10): 17.

[29] Helseth, S., Haraldstad, K., and Christophersen, K. 2015. "A Cross-sectional Study of Health Related Quality of Life and Body Mass Index in Norwegian School Sample (8-18 Years): A Comparison of Child and Parent Perspective." Health Qual Life Outcomes 13: 47.

[30] Lu, H.-X., Wong, M., Lo, E. C. M., et al. 2013. "Risk Indicators of Oral Health Status among Young Adults Aged 18 Years Analyzed by Negative Binomial Regression." BMC Oral Health 13: 40.

[31] Bhola, R., and Malhotra, R. 2014. "Dental Procedures, Oral Practices and Associated Anxiety: A Study on Late-Teenagers." Osong Public Health Res Perspect 5 (4): 219-32.

[32] Winefield, A. R., Delfabbro, P. H., Winefield, A. A., Plueckhahn, T., and Malvaso, C. G. 2015. "Adolescent Predictors of Satisfaction with Social Support Six Years Later: An Australian Longitudinal Study." J Adolesc 44: 70-6.

[33] Dumitrescu, A. L., Dogaru, C. B., Duta, C., et al. 2014. "Impact of Emotional Neglect and Self-silencing on Body Mass Index and Oral Health Behaviors: A Structural Equation Model Analysis in Undergraduate Students." Procedia-Social and Behavioral Sciences 127: 363-7. 